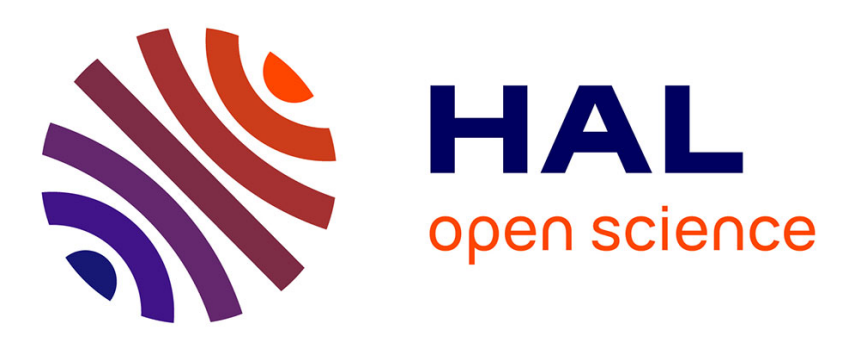

\title{
Bromoalkyl ATRP initiator activation by inorganic salts: experiments and computations
}

Jirong Wang, Jianyu Han, Haiyan Peng, Xiangying Tang, Jintao Zhu, Rong-Zhen Liao, Xiaolin Xie, Zhigang Xue, Christophe Fliedel, Rinaldo Poli

\section{- To cite this version:}

Jirong Wang, Jianyu Han, Haiyan Peng, Xiangying Tang, Jintao Zhu, et al.. Bromoalkyl ATRP initiator activation by inorganic salts: experiments and computations. Polymer Chemistry, 2019, 10 (19), pp.2376-2386. 10.1039/C9PY00113A . hal-02335256

\section{HAL Id: hal-02335256 https://hal.science/hal-02335256}

Submitted on 30 Oct 2020

HAL is a multi-disciplinary open access archive for the deposit and dissemination of scientific research documents, whether they are published or not. The documents may come from teaching and research institutions in France or abroad, or from public or private research centers.
L'archive ouverte pluridisciplinaire HAL, est destinée au dépôt et à la diffusion de documents scientifiques de niveau recherche, publiés ou non, émanant des établissements d'enseignement et de recherche français ou étrangers, des laboratoires publics ou privés. 


\title{
Bromoalkyl ATRP initiator activation by inorganic salts: experiments and computations
}

Received 00th January 20xx, Accepted 00th January 20xx DOI: $10.1039 / \times 0 \times x 00000 x$

\author{
Jirong Wang, ${ }^{\text {a }}$ Jianyu Han, ${ }^{\text {ta }}$ Haiyan Peng, ${ }^{a}$ Xiangying Tang, ${ }^{\text {a }}$ Jintao Zhu, ${ }^{\text {a }}$ Rong-Zhen Liao, ${ }^{\text {a }}$ Xiaolin \\ Xie, ${ }^{a}$ Zhigang Xue, ${ }^{* a}$ Christophe Fliedel ${ }^{b}$ and Rinaldo Poli*b
}

\begin{abstract}
Ethyl $\alpha$-bromophenylacetate (EBrPA) is able to initiate the bulk radical polymerisation of methyl methacrylate (MMA) under thermal conditions $\left(90^{\circ} \mathrm{C}\right)$ in the presence of a variety of simple alkali or alkaline-earth metal or $n \mathrm{Bu}_{4} \mathrm{~N} \mathrm{salts}\left(\mathrm{Mt}^{+} \mathrm{X}^{-}\right.$with $\mathrm{X}^{-}=$ chloride, bromide, iodide, carbonate, bicarbonate, sulfate, bisulfate, nitrate, hydroxide and hexafluorophosphate). Chain growth is controlled only when using iodide salts, which also gives one of the highest polymerisation rates. Using a substoichiometric amount of Lil as activator, the polymerisation rate is unaffected by the Lil/initiator ratio when the initiator is cyanoisopropyl iodide (CPI) but scales with the activator amount when using EBrPA. Analysis of these rates in combination with the polymer molecular weights has revealed a LiBr-catalysed halogen exchange between more active PMMA-I and less active PMMA-Br chains. In combination with a computational investigation by DFT methods, these findings demonstrate

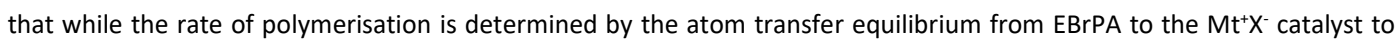
yield $\mathrm{EPA}^{\bullet}$ and $\mathrm{Mt}^{+}\left(\mathrm{BrX}^{*}\right)^{\text {; }}$, controlled chain growth cannot be insured exclusively by the persistent radical effect.
\end{abstract}

\section{Introduction}

Atom transfer radical polymerisation (ATRP) has been intensively investigated in the last two decades thanks to its outstanding capability of producing well-defined polymers with predictable molecular weight as well as narrow molecular weight distribution. ${ }^{1-9}$ There are two complementary ways to initiate the polymerisation, leading to the same moderating equilibrium: a "direct" method where a suitable alkyl halide $\mathrm{R}_{0^{-}}$ $X$ is used as initiator in the presence of an activator (A), which is an acceptor of the halogen atom, and a "reverse" method where a conventional radical initiator (I) produces the primary radical $\left(R_{0}{ }^{\circ}\right)$ in the presence of the oxidized version of the activator $(A-X)$, see Scheme 1 . The moderating equilibrium is characterized by an equilibrium constant $K$, which is the ratio between the activation and deactivation rate constants $k_{\mathrm{a}}$ and $k_{\text {da, }}$ respectively.

In most ATRP implementations, a redox-active transition metal complex in its lower oxidation state has been used as activator species, with copper(I) ${ }^{5}, 7,10,11$ and iron(II) $)^{12-18}$ being the most commonly used central metal ions, owing to their considerable versatility. Iron attracts considerable interest because of its lower cost, greater availability, lower toxicity and higher

\footnotetext{
a. Key Laboratory for Material Chemistry of Energy Conversion and Storage, Ministry of Education, School of Chemistry and Chemical Engineering, Huazhong University of Science and Technology, Wuhan 430074, P. R. China.

b. CNRS, LCC (Laboratoire de Chimie de Coordination), Université de Toulouse, UPS, INPT, 205 Route de Narbonne, BP 44099, F-31077 Cedex 4, Toulouse, France.

+ Present address: Dalian National Laboratory for Clean Energy, Dalian Institute of Chemical Physics, Chinese Academy of Sciences, Dalian 100049, P. R. China.

Electronic Supplementary Information (ESI) available: Tables and figures of experimental and computational results (23 pages).. See DOI: 10.1039/x0xx00000x
}

biocompatibility. ${ }^{19-21}$ However, it has recently become apparent that a controlled polymerisation process initiated by alkyl halides may also occur in the presence of non-metallic activators. One important family is that of photocatalysts, which are excited by light irradiation to become strong reductants, thus able to abstract a halogen atom from an alkyl halide. ${ }^{22-31}$ These systems operate only in the presence of light and are able to function when the transferred halogen atom is chlorine or bromine. Other metal-free ATRP systems, however, have been shown to also operate under thermal conditions, without light.

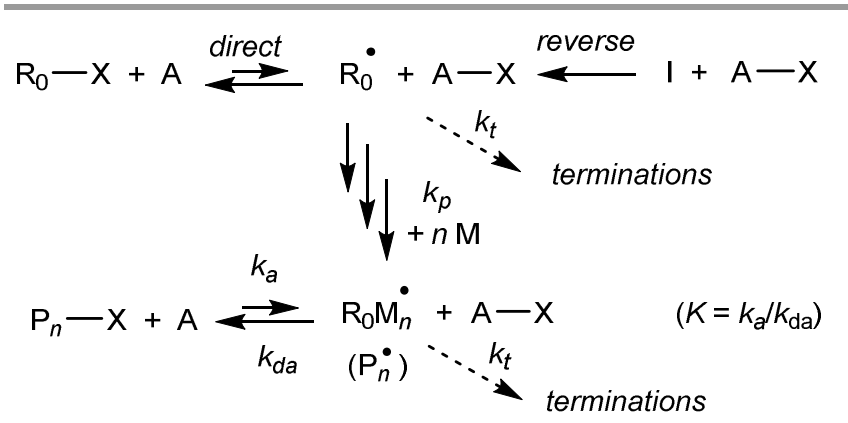

Scheme 1. General mechanism of ATRP.

In this case the catalyst may be phenol or other oxygencontaining antioxidants, ${ }^{32}$ an amine, ${ }^{33-36}$ hexamethylphosphoramide ${ }^{37}$ or a soluble iodide salts with a variety of organic cations such as ammoniums, phosphoniums, sulfoniums, imidazoliums, ${ }^{38}, 39$ substituted quinoliniums, ${ }^{40}$ and choline derivatives, ${ }^{41}$ and even with crown ether-complexed alkali and alkaline earth metals ( $\mathrm{Na}, \mathrm{K}, \mathrm{Cs}, \mathrm{Mg}, \mathrm{Ca}) .{ }^{42}, 43$ Notably, these systems used only alkyl iodides as initiators. The alternative use of an alkyl bromide initiator was shown to proceed, in the presence of sodium iodide, via halogen exchange and 
subsequent activation of the iodoalkane by the iodide catalyst. ${ }^{44,45}$ The use of salts other than iodides as activators has not been described to the best of our knowledge, except for one report involving azide, cyanate and thiocyanate, still in combination with alkyl iodide initiators. ${ }^{46}$ The proposed mechanism involves reversible transfer of the iodine atom to the catalyst, thus forming for instance an amine $\left.\cdots\right|^{\bullet}$ or $\mathrm{Mt}^{+} \mathrm{I}_{2}{ }^{-}$ $(\mathrm{Mt}=$ metal $)$ system as radical trapping agent and the deactivation process involves reverse transfer of the I atom to the polymer radical chain end. It has also been proposed that the above species dimerize, e.g. to (amine) ${ }_{2} \cdots I_{2}$, and that the dimer may then act as additional deactivator. All these propositions imply a reversible termination mechanism of action, with involvement of the persistent radical effect (PRE). ${ }^{47}$ In the course of studies carried out in our laboratories on salt promoted Fe-catalysed ATRP and more specifically while carrying out control experiments in the absence of the $\mathrm{Fe}$ catalyst, we have discovered the activating action by a variety of different salts on a typical alkyl bromide initiator, ethyl $\alpha$ bromophenylacetate (EBrPA). The results of these experiments, which complement those previously reported for the iodoalkane/iodide salt activation, and a DFT investigation of selected systems, lead to the suggestion that the chain growth for the iodide system, though regulated by the PRE in terms of polymerisation rate, cannot be controlled in terms of target molecular weight, low dispersity and chain-end functionality through the exclusive action of a PRE. We therefore suggest the contribution of a degenerative exchange, as in iodine transfer polymerisation (ITP), to provide the observed control.

\section{Results and Discussion}

\section{(a) Experimental investigations.}

Ethyl $\alpha$-bromophenylacetate (EBrPA) is a commonly used ATRP initiator, able to control the polymerisation of MMA in the presence of suitable activators such as L/Cu' complexes. ${ }^{48}$ It is not efficient for the initiation of MMA polymerisation, at $90^{\circ} \mathrm{C}$, without the addition of activators, as shown by the control experiment in Table 1, entry 1 . Nevertheless, faster radical polymerisation of MMA occurs in the presence of a large variety of inorganic salts (entries 2-36). The radical nature of the process is proven by two parallel experiments run under identical conditions in the presence of $\mathrm{Na}_{2} \mathrm{CO}_{3}$ (same conditions as in Table 1, entry 20). TEMPO was added into one of them after $5 \mathrm{~h}$, when the conversion was $5.3 \%$. After $18 \mathrm{~h}$ of continued polymerisation, the conversion in this reaction did not further increase, whereas that of the parallel experiment increased to $29.2 \%$.

For different salts with the same anion, the PMMA yields vary with the cation nature in ways that seem at least in part related to the salt solubility in the bulk monomer (see for instance the chloride series, entries 2-8, and the bromide series, entries 916). Adding 18-crown-6 (CE) to the polymerisations activated by $\mathrm{NaCl}, \mathrm{KCl}, \mathrm{NaBr}$ and $\mathrm{KBr}$ increased the solubility and also the yield (cf. entries 3 and 4 for $\mathrm{NaCl}, 5$ and 6 for $\mathrm{KCl}, 10$ and 11 for
Table 1. Effect of added salts on the bulk polymerisation of MMA at $90^{\circ} \mathrm{C}$ initiated by EBrPA. ${ }^{a}$

\begin{tabular}{|c|c|c|c|c|c|}
\hline & Additive $^{b}$ & Sol.c & $\mathrm{t} / \mathrm{h}$ & Yield/\% & $M_{n, G P C}\left(M_{n, t h}\right),{ }^{d} \bigoplus$ \\
\hline 1 & - & & 12 & 2.3 & $11.4(0.7), 1.37$ \\
\hline 2 & $\mathrm{LiCl}$ & PS & 12 & 24.2 & $21.0(5.1), 1.60$ \\
\hline 3 & $\mathrm{NaCl}$ & SS & 12 & 12.1 & $10.3(2.7), 2.16$ \\
\hline 4 & $\mathrm{Na}(\mathrm{CE}) \mathrm{Cl}$ & PS & 18 & 26.5 & $624.5(1.5), 1.80$ \\
\hline 5 & $\mathrm{KCl}$ & SS & 12 & 7.8 & $58.5(1.8), 3.73$ \\
\hline 6 & $\mathrm{~K}(\mathrm{CE}) \mathrm{Cl}$ & PS & 9 & $9.8^{e}$ & $10.2(2.0), 1.63$ \\
\hline 7 & $\mathrm{MgCl}_{2}$ & SS & 12 & 3.4 & $18.9(0.9), 1.77$ \\
\hline 8 & $\mathrm{CaCl}_{2}$ & SS & 12 & 26.9 & $134.5(5.6), 2.64$ \\
\hline 9 & $\mathrm{LiBr}$ & PS & 12 & 9.6 & $26.6(2.2), 1.34$ \\
\hline 10 & $\mathrm{NaBr}$ & SS & 12 & 13.0 & $62.6(2.8), 1.71$ \\
\hline 11 & $\mathrm{Na}(\mathrm{CE}) \mathrm{Br}$ & $S$ & 8 & 26.3 & $124.2(5.5), 1.48$ \\
\hline 12 & $\mathrm{KBr}$ & SS & 18 & 8.1 & $146.8(1.9), 2.16$ \\
\hline 13 & $\mathrm{~K}(\mathrm{CE}) \mathrm{Br}$ & PS & 18 & 37.6 & $47.0(7.8), 1.69$ \\
\hline 14 & $\mathrm{RbBr}$ & SS & 12 & 5.1 & 20.4(1.3), 1.68 \\
\hline 15 & $\mathrm{CsBr}$ & SS & 12 & 4.8 & $17.8(1.2), 1.76$ \\
\hline 16 & $n \mathrm{Bu}_{4} \mathrm{NBr}$ & S & 18 & 36.7 & $655.4(7.6), 2.49$ \\
\hline 17 & $\mathrm{Lil}^{\mathrm{f}}$ & $S$ & 9 & 72.8 & 7.3(6.3), 1.10 \\
\hline 18 & $\mathrm{Nal}$ & PS & 12 & 32.0 & $6.9(6.7), 1.73$ \\
\hline 19 & $\mathrm{KI}$ & PS & 12 & 22.5 & $5.2(4.8), 1.41$ \\
\hline 20 & $\mathrm{Na}_{2} \mathrm{CO}_{3}$ & SS & 12 & 21.9 & $483.2(4.6), 2.46$ \\
\hline 21 & $\mathrm{~K}_{2} \mathrm{CO}_{3}$ & SS & 12 & 21.1 & $523.5(4.5), 2.78$ \\
\hline 22 & $\mathrm{Rb}_{2} \mathrm{CO}_{3}$ & SS & 12 & 30.6 & $58.7(6.4), 1.76$ \\
\hline 23 & $\mathrm{Cs}_{2} \mathrm{CO}_{3}$ & SS & 12 & 19.5 & $498.7(4.2), 2.43$ \\
\hline 24 & $\mathrm{NaHCO}_{3}$ & SS & 18 & 2.7 & $37.9(0.8), 1.70$ \\
\hline 25 & $\mathrm{KHCO}_{3}$ & SS & 18 & 6.5 & $497.6(1.5), 1.82$ \\
\hline 26 & $\mathrm{KOH}$ & SS & 5 & 13.9 & 541.2(3.0), 2.91 \\
\hline 27 & $\mathrm{~K}(\mathrm{CE}) \mathrm{OH}$ & PS & 3.5 & 37.5 & $122.9(7.8), 1.57$ \\
\hline 28 & $\mathrm{Na}_{2} \mathrm{SO}_{4}$ & SS & 12 & 9.6 & $234(2.2), 1.67$ \\
\hline 29 & $\mathrm{~K}_{2} \mathrm{SO}_{4}$ & SS & 5 & 17.6 & $408.7(3.8), 1.54$ \\
\hline 30 & $\mathrm{Rb}_{2} \mathrm{SO}_{4}$ & SS & 12 & 10.4 & $517.4(2.3), 1.61$ \\
\hline 31 & $\mathrm{Cs}_{2} \mathrm{SO}_{4}$ & SS & 12 & 12.6 & $127.6(3.4), 3.9$ \\
\hline 32 & $\mathrm{NaHSO}_{4}$ & SS & 12 & 18.3 & $1054(3.9), 1.34$ \\
\hline 33 & $\mathrm{NaNO}_{3}$ & SS & 12 & 13.2 & $1166(2.9), 1.56$ \\
\hline 34 & $\mathrm{KNO}_{3}$ & SS & 12 & 18.8 & $105.8(4.0), 1.68$ \\
\hline 35 & $\mathrm{NaPF}_{6}$ & SS & 18 & 60 & $202.5(12.3), 2.47$ \\
\hline 36 & $n \mathrm{Bu}_{4} \mathrm{NPF}_{6}$ & $S$ & 18 & 9.4 & $358.89(2.1), 2.26$ \\
\hline
\end{tabular}

${ }^{\mathrm{a} C o n d i t i o n s: ~}[\mathrm{MMA}]:[\mathrm{EBrPA}]:[\mathrm{Salt}]=200: 1: 2, \mathrm{~T}=90^{\circ} \mathrm{C} .{ }^{\mathrm{b}} \mathrm{CE}=$ crown ether $(18-$ crown-6). ${ }^{\mathrm{c}} \mathrm{SS}=$ sparingly soluble, $\mathrm{PS}=$ partly soluble; $\mathrm{S}=$ fully soluble (at the polymerisation temperature). ${ }^{\mathrm{d} B o t h}$ in $\mathrm{Kg} / \mathrm{mol}$. ${ }^{\text {e }}$ Yield $=22.8 \%$ after $18 \mathrm{~h}, \mathrm{Mn}, \mathrm{GPC}=$ 34.1, $\mathrm{\Xi}=1.89 .{ }^{\mathrm{f}}[\mathrm{MMA}]:[\mathrm{EBrPA}]:[\mathrm{Lil}]=100: 1: 2$.

$\mathrm{NaBr}$ and 12 and 13 for $\mathrm{KBr}$ ). For the bromide series, the highest yields were achieved with the fully soluble $n \mathrm{Bu}_{4} \mathrm{~N}^{+}$salt (entry 16) and with $\mathrm{K}(\mathrm{CE}) \mathrm{Br}$ (entry 13 ). The solubility of the various salts in MMA, as well as in other low-polarity solvents, is not available to the best of our knowledge. In propylene carbonate, which has a much higher permittivity $(\varepsilon=64.4)$, the alkali halide 
solubility varies non-monotonically as $\mathrm{Li}>\mathrm{Cs}>\mathrm{K}>\mathrm{Rb}>\mathrm{Na}$ for the chloride series and as $\mathrm{Li}>>\mathrm{Rb} \sim \mathrm{Cs}>\mathrm{Na} \sim \mathrm{K}$ for the bromide series. ${ }^{49}$

In addition to the solubility effect, the cation nature also appears to influence the activation process, as suggested by the recovered polymer properties ( $\mathrm{M}_{n}$ and $\boxplus$ ). Whereas the PMMAs obtained with the bromide activators (entries 9-16) have approximately the same dispersity and $M_{n, G P C} / M_{n, t h}$ ratios (with the exception of $n \mathrm{Bu}_{4} \mathrm{NBr}$ for which these parameters are significantly higher), those obtained for the chloride series (entries 2-8) show more disparate properties with $Đ$ values from $1.60(\mathrm{Li})$ to $3.73(\mathrm{~K})$ and $\mathrm{M}_{\mathrm{n}, \mathrm{GPC}} / \mathrm{M}_{\mathrm{n}, \mathrm{th}}$ from $3.8(\mathrm{Na})$ to 416 $(\mathrm{Na}(\mathrm{CE}) \mathrm{Cl})$. Both solubility and cation nature were shown to also affect the MMA polymerisation initiated by cyanoisopropyl iodide (CPI) in the presence of a variety of activating iodide salts. ${ }^{43} \mathrm{~A}$ monitoring of the polymerisation carried out in the presence of $\mathrm{KBr}$ showed increasing molecular masses and decreasing $\bigoplus$ values with conversion (see Table $S 1$ ), suggesting the presence of a PRE, but the $M_{n, G P C} / M_{n, t h}$ and $\emptyset$ values are far from those expected for a controlled chain growth.

The use of iodide salts (entries 17-19) leads to a similar activation phenomenon. The polymerisation is slightly faster with $\mathrm{Nal}$ than with $\mathrm{KI}$, which is the same trend previously reported for the polymerisation initiated by $\mathrm{CPI} / \mathrm{Mt}^{+} \mathrm{I}^{-}, 43$ but Lil leads to an even greater activation. This again suggests a major role of the salt solubility in the activation process. The solubility for these salts is known to vary as $\mathrm{KI}<\mathrm{Nal}<\mathrm{Lil}$ in solvents such as acetone $\mathrm{e}^{50}$ and $\mathrm{C}_{1}-\mathrm{C}_{5}$ alcohols. ${ }^{51} \mathrm{~A}$ point of greater interest, however, is that the polymers produced in these cases show significantly lower dispersities and the molar masses are in better agreement with the expected values for a controlled chain growth. This confirms the previously published $\mathrm{Na}(\mathrm{CE}) \mathrm{I}$ effect on the thermal polymerisation of MMA and other monomers ${ }^{44}$ and on the photopolymerisation of PEGMA, ${ }^{45}$ both initiated by EBrPA. In the presence of $\mathrm{Na}$ (CE)I. EBrPA undergoes a rapid halogen exchange process (equation $1, \mathrm{Mt}^{+}=\mathrm{Na}(\mathrm{CE})^{+}$) to yield $\mathrm{Na}(\mathrm{CE}) \mathrm{Br}$ and ethyl $\alpha$-iodophenylacetate (EIPA), which is then capable of controlling the polymerisation of MMA in the presence of excess $\mathrm{Na}(\mathrm{CE}) \mathrm{I} .{ }^{44}$

\section{$\mathrm{PhCH}(\mathrm{Br}) \mathrm{COOEt}+\mathrm{Mt}^{+} \mathrm{I} \rightarrow \mathrm{PhCH}(\mathrm{I}) \mathrm{COOEt}+\mathrm{Mt}^{+} \mathrm{Br}$}

The EBrPA activation is not limited to halide salts. As shown in Table 1, also carbonates (entries 20-23), bicarbonates (entries 24 and 25), $\mathrm{KOH}$ (entries 26 and 27), sulphates (entries 28-31), sodium bisulphate (entry 32 ), nitrates (entries 33 and 34 ) and even hexafluorophosphates (entries 35 and 36) lead to activation. The much greater conversion observed in the presence of the sparingly soluble $\mathrm{NaPF}_{6}$ (entry 35) than of the fully soluble $n \mathrm{Bu}_{4} \mathrm{NPF}_{6}$ (entry 36 ) underlines a possible contribution of the cation to the activation process. Only $\mathrm{NaHCO}_{3}$ (entry 24) gave a very low yield, similar to that of the control. With $\mathrm{KOH}$, on the other hand, the polymerisation is one of the fastest within Table 1, with a 37.5\% monomer conversion in only 3.5 hours when 18-crown-6 is present (entry 27). Additional monitoring experiments were carried out for the polymerisations in the presence of $\mathrm{Na}_{2} \mathrm{CO}_{3}$ and $\mathrm{Cs}_{2} \mathrm{SO}_{4}$ (see Table S1), with similar results relative to $\mathrm{KBr}$.
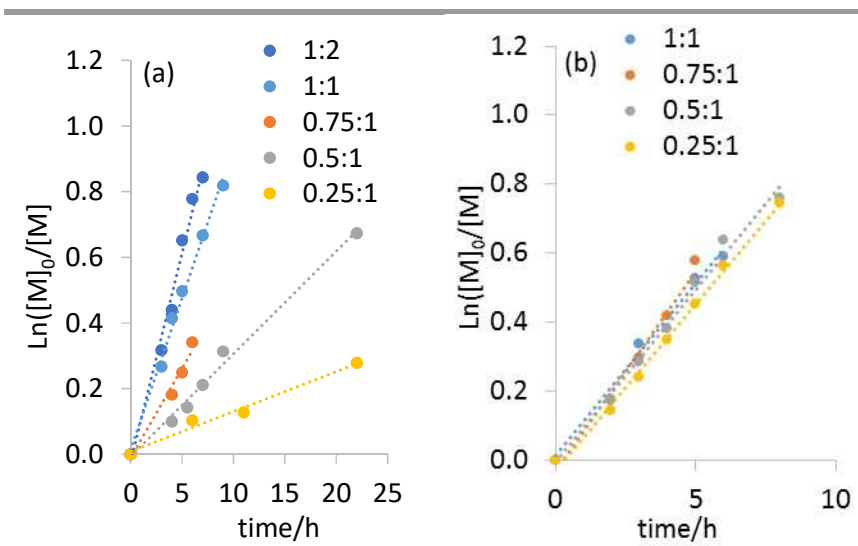

Figure 1. First-order plots of the bulk MMA polymerisation at $70^{\circ} \mathrm{C}$, initiated by (a) EBrPA or (b) CPI, using [MMA]:[initiator]:[Lil] = 100:1:x (x=1,0.75, 0.5, 0.25).

The MMA polymerisation carried out in the presence of EBrPA and Lil was investigated in greater detail at $70^{\circ} \mathrm{C}$ using different EBrPA:Lil ratios and compared with the corresponding polymerisations carried out in the presence of CPI and Lil run under the same conditions. The Li salt was selected because it is fully soluble in bulk MMA at the polymerisation temperature without the need for a crown ether additive. These polymerisations are closely related to those reported by Goto et al. ${ }^{43,44}$ which involved iodide salts with other cations ( $\mathrm{Na}, \mathrm{K}, \mathrm{Cs}$, $\mathrm{Mg}$ and $\mathrm{Ca}$ ) in the presence of crown ether. The kinetics results are shown in Figure 1, whereas the $M_{n}$ and $Ð$ evolutions with conversion are illustrated in Figure 2 for the polymerisations initiated with EBrPA and in Figure 3 for those initiated with CPI.
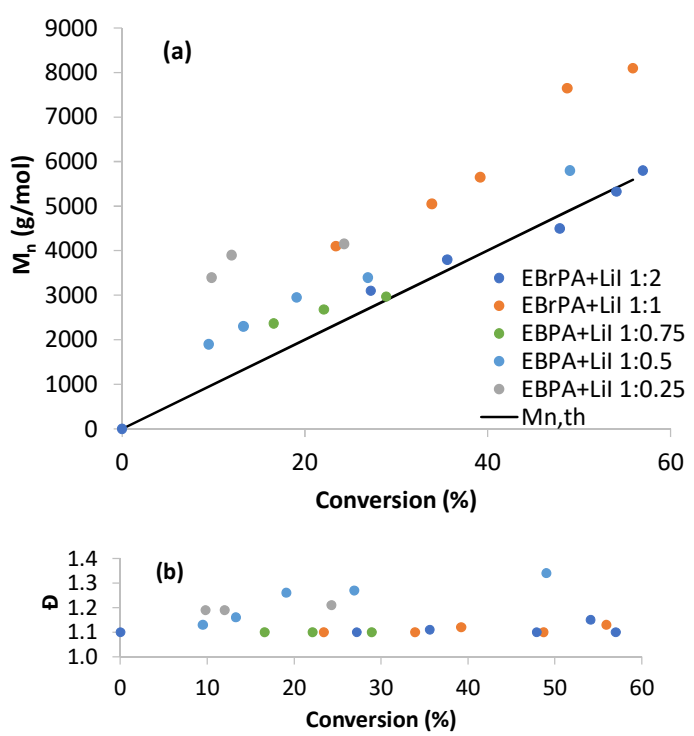

Figure 2. Plots of $M_{n}(a)$ and $\oplus$ (b) vs. conversion for the PMMA obtained from the polymerisations of Figure 1(a) initiated by EBrPA.

There results lead to several interesting considerations. First, we can observe an excellent degree of control for the polymerisations initiated by $\mathrm{CPI}+$ Lil (Figure 3). The CPI consumption, independently monitored by ${ }^{1} \mathrm{H}$ NMR 
spectroscopy, is relatively fast (see Figure S1). Thus, Lil provides rates and a level of control similar to those previously shown for other iodide salts in combination with the iodide initiator. ${ }^{43}$ The polymerisations initiated by EBrPA + Lil yield slightly less satisfactory results (e.g. $Đ$ up to 1.4), but may still be considered to have controlled behaviour (Figure 2). This controlling ability is not quite as good as that shown in the previously published polymerisations with EBrPA (and other bromoalkyl initiators) and Nal. ${ }^{44}$ However, the previously reported polymerisations were carried out in the presence of excess iodide salt, whereas our less controlled polymerizations are those with a substoichiometric amount. The polymerizations with a 1:2 or 1:1 Li/EBrPA ratio are quite well-controlled with $Ð \leq 1.15$ (see further discussion below). An independent ${ }^{1} \mathrm{H}$ NMR monitoring in the absence of monomer revealed the immediate EBrPA disappearance (to yield EIPA, according to the previous investigation), see Figure $\mathrm{S} 2 .{ }^{44}$ Under polymerization conditions, ${ }^{1} \mathrm{H}$ NMR could not give any information on the EIPA disappearance because the most characteristic methyne resonance unfortunately overlaps with one resonance of MMA, which is present in large excess. However, HPLC provided an alternative convenient monitoring of the EBrPA conversion to EIPA and on the disappearance of the latter. The experiment confirms the very fast salt exchange and shows an EIPA disappearance faster than that of CPI (see Figure S1).
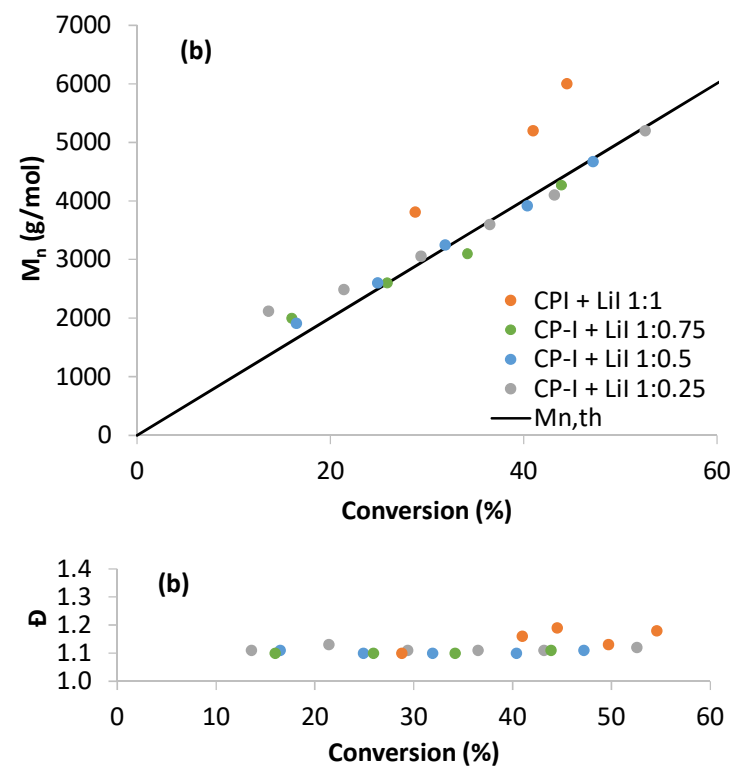

Figure 3. Plots of $M_{n}(a)$ and $Ð$ (b) vs. conversion for the PMMA obtained from the polymerisations of Figure $1(\mathrm{~b})$ initiated by $\mathrm{CPI}$.

One of the most interesting points is that the pseudo-first-order rate constants $\left(k_{\text {obs }}\right)$ for the polymerisations initiated by CPI are very similar to that observed with a 1:1 Lil/CPI ratio when using different substoichiometric amounts of Lil, whereas they scale more or less linearly with the Lil:initiator ratio when using EBrPA as initiator (see Table 2). The observed pseudo-first order rate constant for a controlled polymerisation operating by ATRP (Scheme 1) is given by

$$
k_{o b s}=k_{p} K \frac{[A][P-X]}{[A-X]}
$$

where $\mathrm{P}-\mathrm{X}$ is the polymer dormant chains concentration and the other parameters are defined in Scheme 1. [P-X] is the same in all experiments and approximately equal to initial initiator concentration $\left(\left[R_{0}-X\right]_{0}\right)$. The initial activator concentration will distribute among $\mathrm{A}$ and $\mathrm{A}-\mathrm{X}:[\mathrm{A}]_{0}=[\mathrm{A}]+[\mathrm{A}-\mathrm{X}]$. The observed rate constant does not depend on the total activator concentration, but rather on the $[A] /[A-X]$ ratio. Matyjaszewski has shown that identical rates are obtained by reducing the amount of activator, under conditions in which an external reducing agent is used to regenerate the activator A from A-X. ${ }^{52}$ Thus, the behaviour observed for the CPI + Lil polymerisations is not surprising for a process controlled by ATRP, where the PRE regulates the polymerization rate.

Table 2. Observed rate constants (in $\mathrm{h}^{-1}$ ) for the MMA polymerisation in the presence of Lil for different initiators and initiator:Lil ratios. ${ }^{a}$

$\begin{array}{ccc}\text { Lil:initiator } & \text { Initiator }=\mathrm{CPI} & \text { Initiator }=\mathrm{EBrPA} \\ 1: 2 & & 0.1419 \\ 1: 1 & 0.1145 & 0.0922 \\ 0.75: 1 & 0.0962 & 0.0542 \\ 0.5: 1 & 0.0996 & 0.0313 \\ 0.25: 1 & 0.0997 & 0.0122\end{array}$

a Polymerisations carried out in bulk at $70^{\circ} \mathrm{C}$ with an MMA/initiator ratio of 100 .

The trend of $k_{\text {obs }}$ for the EBrPA-initiated polymerisation, showing a proportional increase with the amount of Lil catalyst, can be rationalized on the basis of the established halogen exchange process (equation 1). ${ }^{44}$ The equilibrium of reaction 1 was previously investigated by Goto et al. using a slight excess of $\mathrm{Nal}$ in a mixed acetone- $d_{3} /$ toluene solvent, ${ }^{44}$ to mimic the permittivity of MMA. They reported extensive but not quantitative exchange after $10 \mathrm{~min}$ at $50^{\circ} \mathrm{C}$, leading to the conclusion that the reaction is reversible. We have carried out the same experiment using Lil (strictly 1 equivalent), which is fully soluble in this mixed solvent, and find an essentially quantitative exchange at $70^{\circ} \mathrm{C}$ (i.e. the temperature used in the polymerization) after $10 \mathrm{~min}$, see $\mathrm{SI}$, Figure S3. The extensive halide exchange is also confirmed by the marginally smaller $k_{\text {obs }}$ value for the EBrPA-initiated polymerization conduced with 1 equivalent of Lil, with respect to the $k_{\text {obs }}$ obtained when using 2 equivalents (Table 2). Therefore, in the presence of $x$ equivalents of Lil, the corresponding amount of EBrPA is transformed into EIPA plus the equivalent amount of $\mathrm{LiBr}$, whereas the other fraction (1- $x$ ) of EBrPA remains unreacted. Therefore, the polymerisation proceeds at a rate that scales linearly with $x$ because only the EIPA is efficiently activated by $\mathrm{LiBr}$ (EBrPA is activated by $\mathrm{LiBr}$ much less effectively, see Table 1 entry 9 , although this process may also slightly contribute to the polymerisation rate). Thus, the rate does not decrease because the activator concentration is decreased. Rather, it decreases because the useful initiator concentration, and ultimately the dormant chain concentration [P-X], is decreased. A further point of interest is that, after the initial and very rapid halogen exchange, no Lil remains present under the hypothesis 
of a quantitative exchange. Indeed, the ${ }^{1} \mathrm{H}$ NMR analysis did not show any detectable EBrPA when the reaction was carried out with the stoichiometric amount of Lil. The generated EIPA and the dormant PMMA-I chains obtained after initiation must be activated by the $\mathrm{LiBr}$ produced by the exchange. As shown in Table 2 , the $k_{\text {obs }}$ values for the polymerisations initiated by EBrPA and CPI with the stoichiometric amount of Lil are approximately the same. This indicates that the PMMA-I bond is activated equally efficiently by Lil and $\mathrm{LiBr}$ (similar $K$ for the ATRP activation equilibrium).

Yet another point of interest comes from the analysis of the molar masses for the polymerisations initiated by EBrPA. As concluded from the analysis of the $k_{\text {obs }}$ values, the concentration of dormant chains corresponds to the concentration of activator. However, the polymer molar masses are in closer agreement with the values expected for the total initial $[\mathrm{MMA}] /[\mathrm{EBrPA}]$ ratio. They are only a bit higher than the target values, as clearly visible in Figure 2, but much smaller than the values expected for the $[\mathrm{MMA}] /[\mathrm{Lil}]$ ratio, particularly for the experiments with the lowest Lil/EBrPA ratios (0.25 and $0.5)$. This means that not only the EIPA molecules produced by the initial halogen exchange, but also the residual EBrPA molecules, eventually produce PMMA chains with a certain degree of control. However, the polymerisation rate is consistent with efficient activation of only the iodineterminated chains. The only way to reconcile these results is to assume that the growing PMMA-I chains can exchange the iodide atom rapidly with the $\mathrm{Br}$ atom of the residual $\mathrm{EBrPA}, \mathrm{a}$ process that may be catalysed by the presence of $\mathrm{LiBr}$ (Scheme 2a), to eventually obtain a mixture of PMMA-I and PMMA-Br in relative amounts that correspond to the initial Lil/EBrPA ratio. During polymerisation, a degenerative halogen exchange between the active PMMA-I chains and the inactive PMMA-Br chains continues to occur (Scheme 2b). A slow rate for this halogen exchange process, relative to the rate of chain growth, is expected to lead to higher molar masses with a broader distribution. This phenomenon may well be the main reason for the poorer control observed for the EBrPA+Lil-initiated polymerisations, relative to the $\mathrm{CPI}+\mathrm{Lil}$-initiated polymerisations.

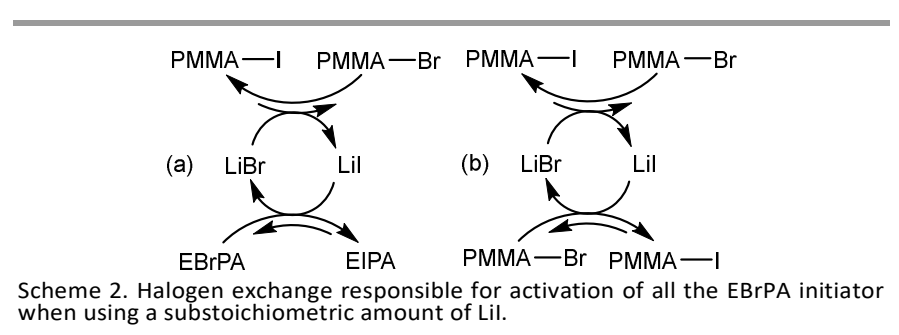
when using a substoichiometric amount of Lil.

\section{(b) Computational studies}

The free energy required to break the $\mathrm{C}-\mathrm{Br}$ bond in EBrPA in the presence of a few selected salts was estimated as the difference between the free energies of the $\left[\right.$ salt $\left.\cdot \mathrm{Br}^{\bullet}+\mathrm{PhCH}^{\bullet} \mathrm{COOEt}\left(\mathrm{EPA}^{\bullet}\right)\right]$ and the [salt + EBrPA] systems, (Scheme 3, equation 4), which is formally the resultant of $\mathrm{C}-\mathrm{Br}$ homolytic bond cleavage in EBrPA (equation 2) and $\mathrm{Br}^{\bullet}$ stabilisation by addition to the salt (equation 3), $\Delta G_{4}=\Delta G_{2}+\Delta G_{3}$. The essential results of these calculations are reported in As shown by the $\Delta G 4$ values in
Erreur! Référence non valide pour un signet. (also shown graphically in the $\mathrm{SI}$, Figure $\mathrm{S} 3$ ), all salts are predicted to exert a significant labilization of the $\mathrm{C}-\mathrm{Br}$ bond in EBrPA, in agreement with the observed polymerisation rate enhancement. There is no linear correlation between the polymerisation rate (Table 1) and the $\mathrm{C}-\mathrm{Br} \mathrm{BDE}$ in the presence of salt (Erreur ! Référence non valide pour un signet.). This is partly a consequence of the above-mentioned approximated model, but the major reason is probably the neglect of solubility issues. For instance, when comparing the labilization effects of $\mathrm{Na}$ and $\mathrm{K}$ salts with the same anion, the $\mathrm{K}$ salt is always predicted to have a greater effect, whereas the activity of the less soluble $\mathrm{KCl}$ and $\mathrm{KBr}$ are lower than those of the more soluble $\mathrm{NaCl}$ and $\mathrm{NaBr}$, respectively. Furthermore, the activity increases in all cases upon addition of crown ether, which enhances the salt solubility. Monomer conversions in the order $\mathrm{K}>\mathrm{Na}$ are experimentally observed for the bicarbonate (entries 24 and 25 ), sulphate (entries 28 and 29) and nitrate (entries 33 and 34) series, whereas the conversions are very close for the carbonate salts (entries 20 and 21). The DFT calculations also indicate a strong activating effect by $\mathrm{KOH}$ and by the carbonates, whereas the rate enhancement by these salts is moderate, again most probably because of solubility issues, as confirmed by the strong rate enhancement for $\mathrm{KOH}$ upon addition of crown ether (Table 1, entry 27 vs. 26).

Table 3 and graphically in Figure S3, whereas the detailed energies and atomic coordinates of all optimized structures are collected in Tables S2 and S3, respectively.

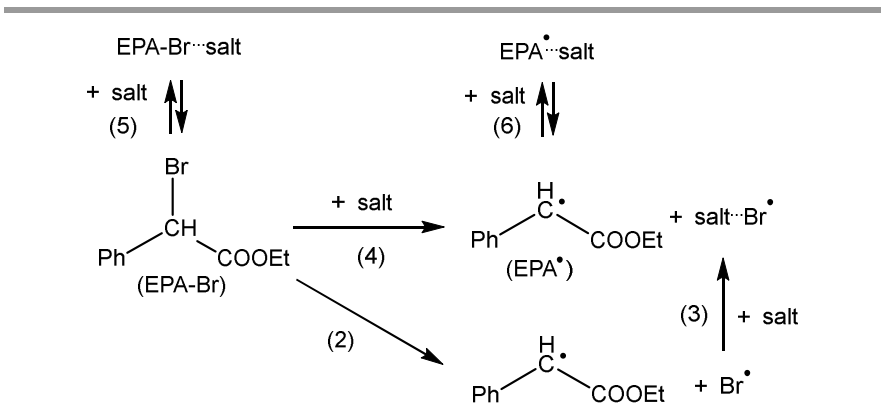

Scheme 3. Model used for the action of salts on the EBrPA activation.

Only one salt molecule was used for the optimisation of the salt, salt· $\mathrm{Br}^{\bullet}$, salt·EBrPA and salt.EPA ${ }^{*}$ systems, without the explicit introduction of solvent (MMA) molecules for the stabilisation of the salt cation. The solvent effect was only considered as a polarisable continuum. Hence, the values obtained by this analysis cannot be considered as realistic, but serve nevertheless as guidance to understand the effect of the salt addition on the initiator activation process. A consequence of using this simplified model is that a significant stabilisation is associated to the formation of the salt.EPA ${ }^{*}$ adducts (Scheme 3, equation 6), which features a relatively strong interaction between the cation and the carbonyl $\mathrm{O}$ atom of the acetate function (e.g. $-11.5 \mathrm{Kcal} / \mathrm{mol}$ for $\mathrm{NaCl}$ or $-8.1 \mathrm{Kcal} / \mathrm{mol}$ for $\mathrm{KCl}$ ). In the absence of cation (i.e. for the free anions), there is no stabilizing interaction (e.g. $\Delta G_{6}=+4.6$ for $\mathrm{Cl}^{-}$). We neglect this interaction because, in the real system, the stabilizing $\mathrm{C}=\mathrm{O} \cdots$ cation interaction can only be established by replacement 
of an equivalent interaction with the MMA molecules in the medium. Therefore, the net stabilisation provided by equation (6) is probably insignificant. The formation of the salt-EBrPA adducts (Scheme 3, equation 5) does not lead to any stabilisation (e.g. $\Delta G_{5}=+14.2$ and $+1.4 \mathrm{kcal} / \mathrm{mol}$ for $\mathrm{Cl}^{-}$and $\mathrm{NaCl}$, respectively) and is therefore equally neglected. The $\Delta G_{5}$ and $\Delta G_{6}$ values for all salts are listed in Table S4. The stabilisation of $\operatorname{Br}^{\bullet}\left(\Delta G_{3}\right)$, on the other hand, is much stronger (vide infra) and does not involve displacement of MMA from the coordination environment of the cation.

As shown by the $\Delta G_{4}$ values in Erreur ! Référence non valide pour un signet. (also shown graphically in the SI, Figure S3), all salts are predicted to exert a significant labilization of the $\mathrm{C}-\mathrm{Br}$ bond in EBrPA, in agreement with the observed polymerisation rate enhancement. There is no linear correlation between the polymerisation rate (Table 1 ) and the $\mathrm{C}-\mathrm{Br} \mathrm{BDE}$ in the presence of salt (Erreur ! Référence non valide pour un signet.). This is partly a consequence of the above-mentioned approximated model, but the major reason is probably the neglect of solubility issues. For instance, when comparing the labilization effects of $\mathrm{Na}$ and $\mathrm{K}$ salts with the same anion, the $\mathrm{K}$ salt is always predicted to have a greater effect, whereas the activity of the less soluble $\mathrm{KCl}$ and $\mathrm{KBr}$ are lower than those of the more soluble $\mathrm{NaCl}$ and $\mathrm{NaBr}$, respectively. Furthermore, the activity increases in all cases upon addition of crown ether, which enhances the salt solubility. Monomer conversions in the order $\mathrm{K}>\mathrm{Na}$ are experimentally observed for the bicarbonate (entries 24 and 25), sulphate (entries 28 and 29) and nitrate (entries 33 and 34) series, whereas the conversions are very close for the carbonate salts (entries 20 and 21). The DFT calculations also indicate a strong activating effect by $\mathrm{KOH}$ and by the carbonates, whereas the rate enhancement by these salts is moderate, again most probably because of solubility issues, as confirmed by the strong rate enhancement for $\mathrm{KOH}$ upon addition of crown ether (Table 1 , entry 27 vs. 26).
Table 3. DFT calculated Gibbs energy changes (in $\mathrm{kcal} / \mathrm{mol}$ ) for equations 3 and 4 (Scheme 3).

\begin{tabular}{|c|c|c|}
\hline Salt/Anion & $\Delta G_{3}$ & $\Delta G_{4}$ \\
\hline- & - & $52.9^{a}$ \\
\hline $\mathrm{LiCl}$ & -12.6 & 40.2 \\
\hline $\mathrm{NaCl}$ & -15.8 & 37.1 \\
\hline $\mathrm{KCl}$ & -18.5 & 34.3 \\
\hline $\mathrm{Cl}^{-}$ & -22.7 & 30.2 \\
\hline $\mathrm{LiBr}$ & -17.7 & 35.2 \\
\hline $\mathrm{NaBr}$ & -19.5 & 33.4 \\
\hline $\mathrm{KBr}$ & -21.6 & 31.3 \\
\hline $\mathrm{Br}^{-}$ & -22.9 & 29.9 \\
\hline Lil & -21.5 & 31.4 \\
\hline Nal & -20.1 & 32.8 \\
\hline $\mathrm{KI}$ & -22.5 & 30.3 \\
\hline $\mathrm{I}^{-}$ & -20.9 & 31.2 \\
\hline $\mathrm{Na}_{2} \mathrm{CO}_{3}$ & -33.7 & 19.2 \\
\hline $\mathrm{K}_{2} \mathrm{CO}_{3}$ & -44.8 & 8.1 \\
\hline $\mathrm{NaHCO}_{3}$ & -3.0 & 49.8 \\
\hline $\mathrm{KHCO}_{3}$ & -13.2 & 39.7 \\
\hline $\mathrm{KOH}$ & -42.4 & 10.5 \\
\hline $\mathrm{Na}_{2} \mathrm{SO}_{4}$ & -16.0 & 36.9 \\
\hline
\end{tabular}

Views of the optimized geometries and key electronic parameters of the (salt $\cdot \mathrm{Br}^{\bullet}$ ) molecules are collected in Figure 4 and Table 4. Adducts with most 1:1 salts ( $\mathrm{LiCl}, \mathrm{LiBr}, \mathrm{Lil}, \mathrm{NaCl}$, $\mathrm{NaBr}, \mathrm{KCl}, \mathrm{KBr}, \mathrm{Nal}, \mathrm{KI}$ and $\mathrm{KOH}$, but not $\mathrm{NaHCO}_{3}$ and $\mathrm{KHCO}_{3}$ ) feature a "three-electron bond" 53 between the $\mathrm{Br}$ atom and the salt anion, such that the adducts may be better represented as $\mathrm{Mt}^{+}(\mathrm{BrX})^{\bullet}-(\mathrm{Mt}=\mathrm{Li}, \mathrm{Na}$ or $\mathrm{K})$.

The metal atom does not have any significant spin density and the positive charge is less than 1 , indicating partial covalence for the cation-anion interaction, which increases as $\mathrm{K}<\mathrm{Na}\left(\mathrm{q}_{\mathrm{K}}>\right.$ $\mathrm{q}_{\mathrm{Na}}$ ). The negative charge and the spin density are shared by the $\mathrm{Br}$ and $\mathrm{X}$ atoms or group. The $\mathrm{Br}$ atom has a lower charge and $\mathrm{a}$ higher spin density than $\mathrm{X}$ in $\mathrm{Mt}^{+}\left(\mathrm{BrCl}^{\circ}\right)$-, equivalent values in the symmetric $\mathrm{Mt}^{+}\left(\mathrm{Br}_{2}{ }^{\circ}\right)^{-}$, and an opposite trend is observed in $\mathrm{Mt}^{+}(\mathrm{Brl})^{-}$. This is as expected from the atom electronegativities. In this respect, the $\mathrm{Mt}^{+}\left(\mathrm{Brl}^{\circ}\right)^{-}$compounds would formally be better described as $\left(\mathrm{Mt}^{+} \mathrm{Br}-\right) \cdot 1^{\bullet}$ than as $\left(\mathrm{Mt}^{+} \mathrm{I}^{-}\right) \cdot \mathrm{Br}^{\bullet}$, although the $\mathrm{Mt}^{+}\left(\mathrm{IBr}^{\circ}\right)^{-}$representation is to be preferred. Greater $\mathrm{C}-\mathrm{Br}$ bond labilization is observed in the order $\mathrm{Li}^{+}$salt $<\mathrm{Na}^{+}$salt $<\mathrm{K}^{+}$salt $<$ free ion, particularly when $X=\mathrm{Cl}$ and less so when $X=\mathrm{Br}$, whereas when $X=I$ the cation has a very small effect. In parallel, the $\mathrm{Br}-\mathrm{X}$ bond distances in $\left.(\mathrm{BrX})^{*}\right)^{-}$gets shorter along the same order $\left(\mathrm{Li}^{+}\right.$salt $>\mathrm{Na}^{+}$salt $>\mathrm{K}^{+}$salt $>$free ion $)$. The $\mathrm{K}^{+}\left(\mathrm{BrOH}^{\bullet}\right)^{-}$ adduct features a greater charge and a lower spin density on $\mathrm{Br}$, in agreement with the lower "group electronegativity" of $\mathrm{OH}$ relative to $\mathrm{Br} .{ }^{54}$ 

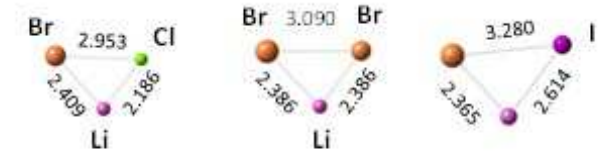

$\mathrm{LiCl} \cdot \mathrm{Br}^{*}$

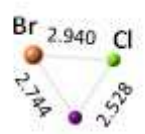

$\mathrm{Na}$

$\mathrm{NaCl} \cdot \mathrm{Br}^{*}$

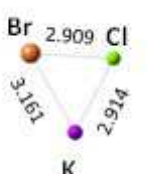

$\mathrm{KCl} \cdot \mathrm{Br} \cdot$
$\mathrm{LiBr} \cdot \mathrm{Br}$ *

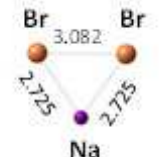

$\mathrm{NaBr} \cdot \mathrm{Br}^{*}$

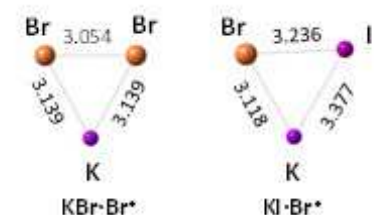

Lil-Br*

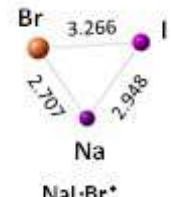

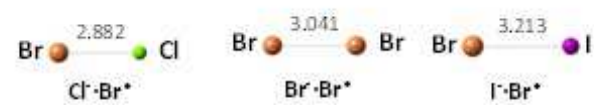

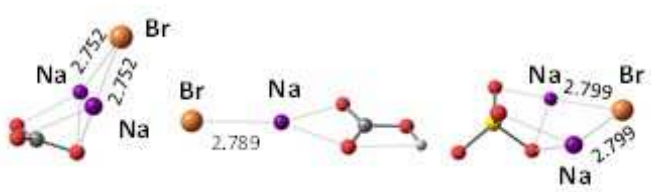

$\mathrm{Na}_{2} \mathrm{CO}_{3} \cdot \mathrm{Br}^{*} \quad \mathrm{NaHCO}_{3} \cdot \mathrm{Br} \mathrm{ra}_{2} \mathrm{SO}_{4} \cdot \mathrm{Br}^{*}$

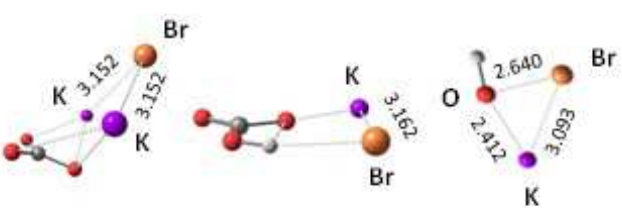

$\mathrm{K}_{2} \mathrm{CO}_{3} \cdot \mathrm{Br}^{*} \quad \mathrm{KHCO}_{3} \cdot \mathrm{Br}^{*} \quad \mathrm{KOH} \cdot \mathrm{Br}$ *

Figure 4. Views of the optimized salt $\cdot \mathrm{Br}^{\bullet}$ geometries with selected interatomic distances in $\AA$.

In the $\mathrm{Br}^{\bullet}$ adducts with the $2: 1$ salts (carbonates and sulphate), the $\mathrm{Br}$ atom interacts only with the metal cations. The spin density on the $\mathrm{Br}$ atom is strongly reduced (to 0.294) in the $\mathrm{Na}_{2} \mathrm{SO}_{4}$ adduct and complete electron transfer is indicated for the $\mathrm{Na}_{2} \mathrm{CO}_{3}$ and $\mathrm{K}_{2} \mathrm{CO}_{3}$ adducts, which can therefore be formally described as adducts of $\mathrm{M}^{+} \mathrm{Br}^{-}$with $\mathrm{M}^{+}\left(\mathrm{CO}_{3}{ }^{\circ}\right)^{-}$. In these adducts, the spin density is distributed among the dianion $\mathrm{O}$ atoms. The bicarbonates feature two different geometries for the $\mathrm{Na}$ and $\mathrm{K}$ salts, a "linear" one with a single $\mathrm{Br} \cdots \mathrm{Na}$ interaction in the first case and a "bent" one with $\mathrm{Br} \cdots \mathrm{K}$ and $\mathrm{Br} \cdots \mathrm{H}$ interactions in the second one. Both geometries gave stable minima for both cations, but the relative energy is in the opposite order for the $\mathrm{Na}$ and $\mathrm{K}$ structures. These adducts also show a moderate extent of charge and spin density sharing between $\mathrm{Br}$ and the bicarbonate group. The spin density data in Table 4 indicate partial electron transfer from the $\mathrm{Br}$ atom to the salt anion in the order $\mathrm{Cl}^{-}<\mathrm{Br}^{-}<\mathrm{I}^{-}<\mathrm{OH}^{-}<\mathrm{SO}_{4}{ }^{2-}<\mathrm{CO}_{3}{ }^{2-}$, with the $\mathrm{HCO}_{3}$ ion being located just above $\mathrm{Cl}^{-}$in the $\mathrm{Na}$ series and very close to $\mathrm{OH}^{-}$in the $\mathrm{K}$ series. This electron transfer appears to contribute to a large extent to the stabilisation of the salt $\cdot \mathrm{Br}^{\bullet}$ adduct, but is certainly not the only factor, since the correlation between the spin density parameter and $\Delta G_{3}$ is not linear (see Figure S4).

Table 4. Selected electronic parameters for geometry-optimized salt $\cdot \mathrm{Br} \bullet$ adducts.

\begin{tabular}{|c|c|c|c|c|c|}
\hline Salt & $\mathrm{qm}^{\mathrm{a}}$ & $\mathrm{q}_{\mathrm{Br}}^{\mathrm{b}}$ & $\alpha_{\mathrm{Br}}{ }^{\mathrm{c}}$ & $q x^{d}$ & $\alpha x^{e}$ \\
\hline $\mathrm{Cl}^{-} \cdot \mathrm{Br}^{\bullet}$ & - & -0.474 & 0.561 & -0.526 & 0.439 \\
\hline $\mathrm{LiCl} \cdot \mathrm{Br}^{\bullet}$ & 0.454 & -0.198 & 0.595 & -0.256 & 0.421 \\
\hline $\mathrm{NaCl} \cdot \mathrm{Br}^{\bullet}$ & 0.666 & -0.295 & 0.587 & -0.371 & 0.425 \\
\hline $\mathrm{KCl} \cdot \mathrm{Br}^{\bullet}$ & 0.854 & -0.379 & 0.582 & -0.475 & 0.423 \\
\hline $\mathrm{Br}^{-} \cdot \mathrm{Br}^{\bullet}$ & - & -0.500 & 0.500 & -0.500 & 0.500 \\
\hline $\mathrm{LiBr} \cdot \mathrm{Br}^{\bullet}$ & 0.495 & -0.247 & 0.512 & -0.247 & 0.512 \\
\hline $\mathrm{NaBr} \cdot \mathrm{Br}^{\bullet}$ & 0.687 & -0.343 & 0.510 & -0.343 & 0.510 \\
\hline $\mathrm{KBr} \cdot \mathrm{Br}^{\bullet}$ & 0.864 & -0.432 & 0.505 & -0.432 & 0.505 \\
\hline $\mathrm{I} \cdot \mathrm{Br}^{\bullet}$ & - & -0.503 & 0.480 & -0.497 & 0.520 \\
\hline $\mathrm{Lil} \cdot \mathrm{Br} \bullet$ & 0.491 & -0.329 & 0.401 & -0.162 & 0.618 \\
\hline $\mathrm{Nal} \cdot \mathrm{Br}^{\bullet}$ & 0.683 & -0.405 & 0.422 & -0.278 & 0.596 \\
\hline $\mathrm{KI} \cdot \mathrm{Br}^{\bullet}$ & 0.880 & -0.487 & 0.436 & -0.384 & 0.575 \\
\hline $\mathrm{Na}_{2} \mathrm{CO}_{3} \cdot \mathrm{Br} \cdot$ & 0.567 & -0.611 & 0.000 & -0.523 & 1.034 \\
\hline $\mathrm{K}_{2} \mathrm{CO}_{3} \cdot \mathrm{Br}^{\bullet}$ & 0.761 & -0.802 & 0.000 & -0.719 & 1.022 \\
\hline $\mathrm{NaHCO}_{3} \cdot \mathrm{Br}^{\bullet}$ & 0.563 & -0.278 & 0.558 & -0.286 & 0.457 \\
\hline $\mathrm{KHCO}_{3} \cdot \mathrm{Br} \cdot$ & 0.856 & -0.534 & 0.396 & -0.323 & 0.610 \\
\hline $\mathrm{Na}_{2} \mathrm{SO}_{4} \cdot \mathrm{Br}^{\bullet}$ & 0.613 & -0.479 & 0.294 & -0.747 & 0.727 \\
\hline $\mathrm{KOH} \cdot \mathrm{Br}^{\bullet}$ & 0.849 & -0.587 & 0.392 & -0.262 & 0.613 \\
\hline
\end{tabular}

${ }^{a}$ Mulliken change on the metal atom ( $\mathrm{Na}$ or $\mathrm{K}$ ). ${ }^{\mathrm{b}}$ Mulliken charge on the $\mathrm{Br}$ atom. ${ }^{c}$ Mulliken spin density on the $\mathrm{Br}$ atom. ${ }^{\mathrm{d}}$ Total Mulliken charge on the salt anion. ${ }^{\mathrm{e}}$ Total Mulliken spin density on the salt anion.

The experiments carried out in the presence of iodide salts lead to halogen exchange (equation 1), as shown in previous work. ${ }^{44}$ It is well-established that this process is endoergic in a homogeneous medium ${ }^{55}$ and this is confirmed by our DFT calculations: $\Delta G_{1}=+19.8,+10.5,+13.7$ and $+13.5 \mathrm{kcal} / \mathrm{mol}$ when $\mathrm{Mt}^{+}=$absent (free ions), $\mathrm{Li}^{+}, \mathrm{Na}^{+}$and $\mathrm{K}^{+}$, respectively. The reaction occurs in the direction shown in equation 1 thanks to the lower solubility of the bromide salt in low polarity solvents. ${ }^{56}$ After the initiation phase, the polymerisations initiated by EBrPA + LiBr, EBrPA + Lil (via exchange to EIPA + LiBr) and $\mathrm{CPI}+$ Lil proceed by continuous reactivation of the dormant species via the equilibria shown in Scheme 4. The Gibbs energy changes associated to these equilibria have been estimated by replacing the PMMA beyond the last two monomer units with an $\mathrm{H}$ atom. Leaving only the last monomer unit in the calculations led to greater Gibbs energy changes, as predictable on the basis of the known strong penultimate monomer effect for methacrylates. ${ }^{57}$ The results are shown in Scheme 5 .

The rate of polymerisation is proportional to $\left(K_{\mathrm{ATRP}} \cdot k_{\mathrm{p}}\right)\left(k_{\mathrm{p}}=\right.$ propagation rate constant), thus a faster polymerisation is expected for a greater activation equilibrium constant. The results are consistent with a faster polymerisation when initiated by $\mathrm{CPI}+\mathrm{Lil}$ (equation 7c) and a slower one when initiated by EBrPA+LiBr (equation 7a), in agreement with the experimental results. However, a critical analysis of the data reveals two problems. The first one is that the computed $\Delta \mathrm{G}$ 
values for equations 7 are too high. ATRP activation equilibria leading to relatively fast polymerisations require a much smaller total $\Delta G$ gap. For instance, a polymerisation half-life of $10 \mathrm{~h}$ at $90^{\circ} \mathrm{C}$ requires a $\Delta G_{\text {gap }}$ of $29.2 \mathrm{kcal} / \mathrm{mol}$. Given that $\Delta G_{\text {gap }}=\Delta G_{\text {ATRP }}$ $+\Delta G_{p}^{\ddagger}$ and that the activation free energy for the MMA propagation at $90^{\circ} \mathrm{C}$ is estimated as $16.1 \mathrm{kcal} / \mathrm{mol}$ (see $\mathrm{SI}$ section, Table S5), ${ }^{58}$ the required $\Delta G_{\text {ATRP }}$ value for this example would be $13.1 \mathrm{kcal} / \mathrm{mol}$. Indeed, $\Delta G_{\text {ATRP }}$ values close to this, or lower, have been reported for a variety of initiator activations by copper complexes. ${ }^{59,60}$ The second problem is that the value calculated for the mixed halogen system (equation $7 \mathrm{~b}$ ) is closer to that of the bromide system (equation 7a), whereas the experimental behaviour is essentially identical to that of the iodide system (equation 7c). Incidentally, exchanging the halogen atoms on the left hand side of equation 7b (namely, considering the hypothetical isomeric deactivation products PMMA-Br + Lil) yields a less stable system, $3 \mathrm{kcal} / \mathrm{mol}$ higher than PMMA-I + LiBr in Gibbs energy. This is consistent with a polymerisation proceeding via the I-terminated dormant species with continuous reactivation by $\mathrm{LiBr}$, rather than the other way around. We believe that the above discrepancies result from the drastic approximation of the model, especially the neglect of explicit cation-solvent interactions. However, the similar values obtained for the three systems confirm that the ATRP of Br-terminated PMMA by transfer to $\mathrm{LiBr}$ is also a viable process, even though slower than the ATRP of I-terminated PMMA by transfer to $\mathrm{LiBr}$ or Lil.

(a) Initiation by $\mathrm{EBrPA}+\mathrm{LiBr}$

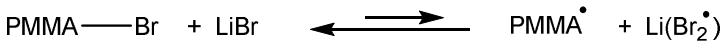

(b) Initiation by EBrPA+Lil

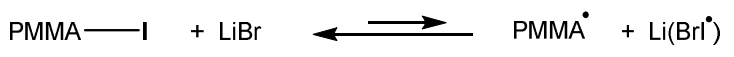

(c) Initiation by CPI+Lil

$\mathrm{PMMA} \longrightarrow \mathrm{I}+\mathrm{Lil} \longleftrightarrow \mathrm{PMMA}^{\bullet}+\mathrm{Li}\left(\mathrm{I}_{2}^{\circ}\right)$

Scheme 4. Atom transfer equilibria regulating the rate of MMA polymerisation with different initiating systems.
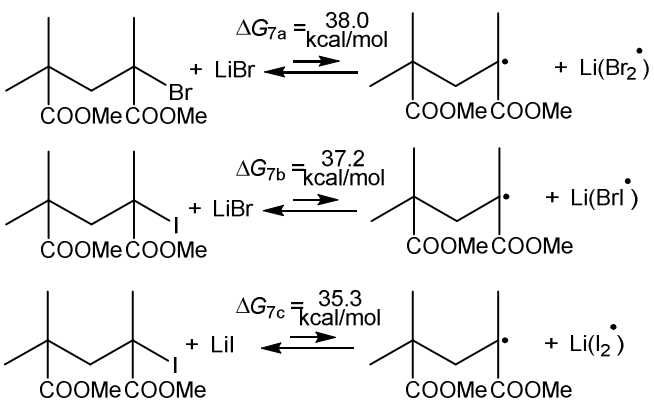

Scheme 5. Computed Gibbs energy changes associated to the equilibria of Scheme 4.

A further mechanistic scenario, as suggested in previous contributions, ${ }^{43,46}$ is that the trapping agent $\mathrm{Li}^{+}\left(\mathrm{XY}^{\bullet}\right)^{-}$. generated by activation of PMMA-Y with $\operatorname{LiX}(X, Y=B r, I)$ disproportionates in a bimolecular process (equation 8 ) and that the resulting $\mathrm{Li}^{+} \mathrm{XY}_{2}{ }^{-}$product acts as an additional deactivator. Our DFT calculations indeed show that this process is favourable $\left(\Delta G_{8}=\right.$ $-5.8 \mathrm{kcal} / \mathrm{mol}$ for $\mathrm{X}=\mathrm{Y}=\mathrm{Br} ;-13.9 \mathrm{kcal} / \mathrm{mol}$ for $\mathrm{X}=\mathrm{Br}, \mathrm{Y}=\mathrm{I} ;-10.1$ $\mathrm{kcal} / \mathrm{mol}$ for $X=Y=1$ ). However, occurrence of this process requires dissociation of the radical caged pair $\left\{\left(\mathrm{PMMA}^{\bullet}\right)\left(\mathrm{LiXY}^{\bullet}\right)\right\}$ generated by the activation of the dormant species. It will ultimately occur when the $\mathrm{Li}\left(\mathrm{XY}^{*}\right)$ species accumulate as a consequence of the irreversible PMMA $^{\bullet}$ terminations, but reaction 8 cannot contribute to the thermodynamics of the initiator activation pre-equilibrium that regulates the polymerisation rate. Similar situations of a "persistent radical" effect insured by a non-persistent radical have been described for other moderating species. ${ }^{61-63}$

$2 \mathrm{Li}^{+}\left(\mathrm{XY}^{*}\right)^{-} \rightarrow \mathrm{Li}^{+} \mathrm{X}^{-}+\mathrm{Li}^{+} \mathrm{XY} \mathrm{Y}^{-}$

\section{(c) Mechanistic discussion}

The results shown above demonstrate that the combination of a bromide initiator, EBrPA, and salts with a variety of anions, most notably bromide, leads to radical generation and to polymerisation with variable rates, which are in certain cases as fast as when iodides are used (e.g. with $\mathrm{KOH}$ ). However, none of these polymerisations show the same level of control as when the dormant species is PMMA-I. Under the hypothesis that the controlled growth rests solely on the PRE, the MtXcatalysed polymerisations that proceed more slowly than those catalysed by $\mathrm{Mtl}$ salts should be even better-controlled, because the lower radical concentration indicated by the slower polymerisation rate should lead to a lower impact of bimolecular terminations. The lack of control for the slower polymerisations would be consistent with a reversible termination mechanism only if, after generation of the active $\left.\mathrm{PMMA}^{\bullet}+\mathrm{Mt}^{+}(\mathrm{BrX})^{\bullet}\right)^{-}$radical pair, deactivation would somehow be slower for all $X$ anions than for iodide. This is, however, against Hammond's postulate, because formation of the more stable (as suggested by the DFT investigations) PMMA-Br + $\mathrm{Mt}^{+} \mathrm{X}^{-}$pair, as opposed to the PMMA-I $+\mathrm{Mt}^{+} \mathrm{X}$ - pair, is expected to proceed through a lower activation barrier. The quality of the obtained polymers (Table 1 ) clearly shows that the PMMA* deactivation by $\left.\mathrm{Mt}^{+}(\mathrm{BrX})^{*}\right)^{-}$for $\mathrm{X} \neq \mathrm{I}$ is not fast enough and the DFT results, in combination with Hammond's postulate, suggest that this deactivation should not be faster when $\mathrm{X}=\mathrm{I}$.

It is known that controlled growth in radical polymerization can only rest on only two principles: (i) reversible termination, in which a PRE reduces the radical concentration and lowers the impact of the bimolecular terminations; (ii) degenerative transfer, which is effective when the rate of associative exchange between free radicals and dormant species is much faster than the rate of propagation. The collective experimental and computational evidence reported in the previous sections shows that a PRE is indeed present, regulating the rate of monomer consumption, but this effect is insufficient to provide chain growth control. On the other hand, PMMA-I chains have been shown to undergo a moderate degree of chain growth control by ITP, a technique resting on the degenerative transfer principle. ${ }^{64}$ Thus, we propose that the special effect of iodine as a dormant chain capping agent in the current system with 
initiation by $\mathrm{EBrPA} / \mathrm{Mt}^{+} \mathrm{I}^{-}$is related to the contribution of ITP. However, the quality of the PMAA produced by the EBrPA/Mt'I initiating system is also inconsistent with the exclusive contribution of ITP, because the dispersity in a pure degenerative transfer process is given by

$$
Đ=1+\frac{1}{C_{t r}}\left(\frac{2}{p}-1\right)
$$

where $p$ is the conversion and $C_{\mathrm{tr}}$ is the transfer constant. The transfer constant for MMA in ITP has been estimated as 2.6 at $80^{\circ} \mathrm{C}, 65$ thus a limiting value of 1.38 can be expected for $Ð$ at complete conversions, whereas the isolated polymers show narrower molecular weight distributions (Figure 2 and Figure 3 ). Quite clearly, the only way to reconcile the observed polymerization rates and parameters $\left(M_{n}, \bigoplus\right)$ for the collective PMMA samples obtained with the EBrPA/Mt ${ }^{+} X^{-}$systems is to invoke a contribution of both a PRE (providing by itself insufficient control for all salts) and a degenerative transfer (effective only for $X=I$, though also insufficient to provide the observed level of control).

\section{Experimental section}

Materials. Methyl methacrylate (MMA, 98+\%, Sinpharm) was passed through a column filled with neutral alumina, dried over calcium hydride $\left(\mathrm{CaH}_{2}\right)$, distilled under reduced pressure and stored in a freezer under argon. Ethyl $\alpha$-bromophenylacetate (EBrPA, 95\%, Alfa Aesar), 2-lodo-2-methylpropionitrile (CP-I, 96\%,TCl), 18-crown-6-ether (CE, 98\%, TCI), 2,2,6,6Tetramethylpiperidine 1-oxy (TEMPO, 98\%, Sigma Aldrich) were used without further purification. Sodium carbonate, sodium bicarbonate, potassium carbonate, potassium bicarbonate, potassium hydroxide, rubidium carbonate, cesium carbonate, sodium sulphate, sodium bisulphate, potassium sulphate, rubidium sulphate, cesium sulphate, sodium nitrate, potassium nitrate, lithium chloride, sodium chloride, potassium chloride, lithium bromide, sodium bromide, potassium bromide, rubidium bromide, cesium bromide, tetra- $n$-butylammonium bromide, sodium iodide, potassium iodide, magnesium chloride, calcium chloride, sodium hexaflurophosphate, tetrabutylammonium hexafluorophosphate (all from Sinpharm) were also used as received.

Measurements. ${ }^{1} \mathrm{H}$ NMR spectroscopy was performed using Bruker AV400, AdvancellI400 HD and Varian INOVA-400 MHz spectrometers with deuterated chloroform as the solvent and tetramethylsilane (TMS) as the standard. The $M_{n, G P C}$ and $M_{w} / M_{n}$ of the polymers were determined by GPC using an Agilent 1100 gel permeation chromatograph, with a column in type of PLgel $79911 \mathrm{GP}-104(7.5 \mathrm{~mm} \times 300 \mathrm{~mm}, 10 \mu \mathrm{m}$ bead size) or a Shimadzu system equipped with a Shimadzu RID-20A refractive index detector with two PSS SDV analytical columns (1000 ̊ and $100000 \AA, 5 \mu \mathrm{m}, 8 \times 300 \mathrm{~mm})$. THF was used as the eluent at a flow rate of $1 \mathrm{~mL} / \mathrm{min}$ at $35^{\circ} \mathrm{C}$. Linear polystyrene standards were used for calibration. HPLC chromatograms were recorded on a Shimadzu LC-2010A(HT) equipped with a BETASIL Silica-100

This journal is (C) The Royal Society of Chemistry 20xx column, using a 95 : 5 pentane/iPrOH solvent mixture as the eluent.

General polymerisation procedure. Unless otherwise stated, a typical system consisted of [monomer] $]_{0} /[\text { initiator] }]_{0} /[\text { activator }]_{0}$ $=200: 1: 2$. A Schlenk flask ( $25 \mathrm{~mL}$ ) was charged under argon with the salt and sealed by a rubber septum. Then the degassed monomer and initiator were added through degassed syringes. The solution was stirred for $30 \mathrm{~min}$ at room temperature. After three freeze-pump-thaw cycles, the flask was immersed in a thermostatic oil bath at $90^{\circ} \mathrm{C}$. At timed intervals, samples were withdrawn from the flask with a degassed syringe. The monomer conversion was determined gravimetrically after the removal of the unconverted monomer under reduced pressure. The resulting residue was diluted with tetrahydrofuran (THF) and then filtered through a column filled with neutral aluminium oxide to remove any insoluble salt. The poly(methyl methacrylate) (PMMA) solution was then precipitated using an excess of $n$-hexane, and these polymers were dried under vacuum overnight at $80^{\circ} \mathrm{C}$ for gel permeation chromatography (GPC) characterisation.

Computational details. The calculations were carried out with the Gaussian 09 program package ${ }^{66}$ using the density functional B3LYP. ${ }^{67}$ Corrections for dispersion were included during optimisation using Grimme's D3 empirical method ${ }^{68}$ (B3LYP$\mathrm{D} 3)$. For geometry optimisations, all elements except $\mathrm{Br}$ and I were described using the $6-31 G(d, p)$ basis sets. The LANL2TZ(f) and LANL08(D) ${ }^{69}$ bases were adopted for the $\mathrm{Br}$ and I atoms, respectively. The solvation and final energies in MMA $(\varepsilon=$ $6.534)^{70}$ were determined as single-point calculations on the optimized structures using the SMD continuum solvation model. Analytic frequency calculations were performed on all the optimized structures under the harmonic approximation to obtain Gibbs free energy corrections at $298.15 \mathrm{~K}$. A correction of 0.003108 hartrees $(1.95 \mathrm{Kcal} / \mathrm{mol})$ was made to the $\mathrm{G}$ values to bring the standard state from $1 \mathrm{~atm}$ to $1 \mathrm{M} .^{71}$

\section{Conclusions}

This investigation has demonstrated that the typical ATRP initiator ethyl $\alpha$-bromophenylacetate (EBrPA) is activated by addition of a wide variety of inorganic compounds $\mathrm{Mt}^{+} \mathrm{X}$ - with production of $\mathrm{PhCH}^{\bullet}(\mathrm{COOEt})$ radicals and $\mathrm{Mt}^{+}\left(\mathrm{XBr}^{*}\right)^{-}$. The activation equilibrium is not as facile as for the previously reported 43 iodoalkyl $+\mathrm{Mt}^{+} \mathrm{I}^{-}$systems and, contrary to those systems, does not lead to controlled polymerisation of MMA, with the exception of the EBrPA + $\mathrm{Mt}^{+} \mathrm{I}^{-}(\mathrm{Mt}=\mathrm{Li}, \mathrm{Na}, \mathrm{K})$ systems which lead to halogen exchange. It has also demonstrated that the iodine-terminated PMMA macromolecules are efficiently activated by these bromide salts. ${ }^{44}$ Thus, bromide salts are a new addition to the list, which comprises iodide, azide, cyanate and thiocyanate salts, ${ }^{46}$ of transition metal-free catalysts for atom transfer radical polymerisation. The investigation carried out with a substoichiometric amount of activator has also revealed the presence of a degenerative halogen exchange between iodine- and bromine-terminated chains, PMMA-I and PMMA-Br. Furthermore, in the previous contributions, $43,44,46$ the operating mechanism was speculated to rest on reversible 
termination and the presence of a PRE, but was not fully clarified. On the basis of the collective experimental and computational results reported in this contribution, notably showing that the EBrPA activation by iodide salts leads to PMMA-I growing chains and that this polymerization is at the same faster and better controlled than those involving other salts, we suggest that the special effect of the iodine atom at the polymer chain end is related to the significant contribution of a degenerative transfer mechanism for the controlled chain growth, as in ITP. ${ }^{64,65}$ However, differently from a classical ITP, where the active radicals are continuously injected into solution from the thermal decomposition of a conventional radical initiator such as AIBN, in the present case the radicals are continuously generated (and subsequently deactivated) from the alkyl halide initiator by atom transfer to the salt catalyst. Therefore, a reversible termination mechanism, which is regulated by the $P R E$, is responsible for the radical generation and for the polymerisation rate. This reversible termination equilibrium is insufficient to insure chain growth control, except for $X=I$ where it contributes to the controlled chain growth together with degenerative transfer, after halogen exchange leading to $\mathrm{PMMA}-\mathrm{I}+\mathrm{Mt}^{+} \mathrm{Br}^{-}$.

\section{Conflicts of interest}

There are no conflicts to declare.

\section{Acknowledgements}

This work was financially supported by the National Natural Science Foundation of China (51622303) and Natural Science Foundation of Hubei Scientific Committee (2018CFA059 and 2016CFA001). We also gratefully acknowledge the CNRS (Centre National de la Recherche Scientifique) for recurrent funding and the China Scholarship Council for a doctoral fellowship to JW (No. 201806160052). This work was granted access to the computational resources of the CICT (Centre Interuniversitaire de Calcul de Toulouse, project CALMIP).

\section{Notes and references}

1. M. Kamigaito, T. Ando and M. Sawamoto, Chem. Rev., 2001, 101, 3689-3745.

2. K. Matyjaszewski and J. H. Xia, Chem. Rev., 2001, 101, 2921-2990.

3. M. Ouchi, T. Terashima and M. Sawamoto, Chem. Rev., 2009, 109, 4963-5050.

4. F. di Lena and K. Matyjaszewski, Progr. Polym. Sci., 2010, 35, 959-1021.

5. K. Matyjaszewski and N. V. Tsarevsky, J. Am. Chem. Soc., 2014, 136, 6513-6533.

6. K. Matyjaszewski, Macromolecules, 2012, 45, 4015-4039.

$7 . \quad$ C. Boyer, N. A. Corrigan, K. Jung, D. Nguyen, T.-K. Nguyen, N. N. M. Adnan, S. Oliver, S. Shanmugam and J. Yeow, Chem. Rev., 2016, 116, 1803-1949.

8. J.-F. Lutz, J.-M. Lehn, E. W. Meijer and K. Matyjaszewski, Nat. Rev. Mater., 2016, 1, 16024.
9. J. M. Ren, T. G. McKenzie, Q. Fu, E. H. H. Wong, J. Xu, Z. An, S. Shanmugam, T. P. Davis, C. Boyer and G. G. Qiao, Chem. Rev., 2016, 116, 6743-6836.

10. H. D. Tang, N. Arulsamy, M. Radosz, Y. Q. Shen, N. V. Tsarevsky, W. A. Braunecker, W. Tang and K. Matyjaszewski, J. Am. Chem. Soc., 2006, 128, 16277-16285.

11. Q. Zhang, P. Wilson, Z. Li, R. McHale, J. Godfrey, A. Anastasaki, C. Waldron and D. M. Haddleton, J. Am. Chem. Soc., 2013, 135, 7355-7363.

12. R. Poli, L. E. N. Allan and M. P. Shaver, Prog. Polym. Sci., 2014, 39, 1827-1845.

13. Z. Xue, D. He and X. Xie, Polym. Chem., 2015, 6, 1660-1687.

14. D. F. Grishin and I. D. Grishin, Polym. Sci. Ser. C, 2015, 57, 32-64.

15. A. Simakova, M. Mackenzie, S. E. Averick, S. Park and K. Matyjaszewski, Angew. Chem. Int. Ed., 2013, 52, 1214812151.

16. X. Pan, N. Malhotra, J. Zhang and K. Matyjaszewski, Macromolecules, 2015, 48, 6948-6954.

17. H. Schroeder and M. Buback, Macromolecules, 2015, 48, 6108-6113.

18. H. Schroeder, K. Matyjaszewski and M. Buback, Macromolecules, 2015, 48, 4431-4437.

19. Y. Shen, H. Tang and S. Ding, Prog. Polym. Sci. , 2004, 29, 1053-1078.

20. K. Schroder, K. Matyjaszewski, K. J. T. Noonan and R. T. Mathers, Green Chem., 2014, 16, 1673-1686.

21. I. Bauer and H.-J. Knölker, Chem. Rev., 2015, 115, 31703387.

22. N. J. Treat, H. Sprafke, J. W. Kramer, P. G. Clark, B. E. Barton, J. R. de Alaniz, B. P. Fors and C. J. Hawker, J. Am. Chem. Soc., 2014, 136, 16096-16101.

23. X. C. Pan, M. Lamson, J. J. Yan and K. Matyjaszewski, ACS Macro Lett., 2015, 4, 192-196.

24. X. C. Pan, C. Fang, M. Fantin, N. Malhotra, W. Y. So, L. A. Peteanu, A. A. Isse, A. Gennaro, P. Liu and K. Matyjaszewski, J. Am. Chem. Soc., 2016, 138, 2411-2425.

25. X. D. Liu, L. F. Zhang, Z. P. Cheng and X. L. Zhu, Polym. Chem., 2016, 7, 689-700.

26. J. C. Theriot, C. H. Lim, H. Yang, M. D. Ryan, C. B. Musgrave and G. M. Miyake, Science, 2016, 352, 1082-1086.

27. R. M. Pearson, C. H. Lim, B. G. McCarthy, C. B. Musgrave and G. M. Miyake, J. Am. Chem. Soc., 2016, 138, 1139911407.

28. X. C. Pan, M. A. Tasdelen, J. Laun, T. Junkers, Y. Yagci and K. Matyjaszewski, Progr. Polym. Sci., 2016, 62, 73-125.

29. C. H. Lim, M. D. Ryan, B. G. McCarthy, J. C. Theriot, S. M. Sartor, N. H. Damrauer, C. B. Musgrave and G. M. Miyake, J. Am. Chem. Soc., 2017, 139, 348-355.

30. J. C. Theriot, B. G. McCarthy, C. H. Lim and G. M. Miyake, Macromol. Rapid Comm., 2017, 38, 1700040.

31. B. L. Ramsey, R. M. Pearson, L. R. Beck and G. M. Miyake, Macromolecules, 2017, 50, 2668-2674.

32. A. Goto, N. Hirai, K. Nagasawa, Y. Tsujii, T. Fukuda and H. Kaji, Macromolecules, 2010, 43, 7971-7978.

33. A. Goto, T. Suzuki, H. Ohfuji, M. Tanishima, T. Fukuda, Y. Tsujii and H. Kaji, Macromolecules, 2011, 44, 8709-8715.

34. A. Ohtsuki, A. Goto and H. Kaji, Macromolecules, 2013, 46, 96-102.

35. L. Lei, M. Tanishima, A. Goto and H. Kaji, Polymers, 2014, 6, 860-872. 
36

A. Goto, S. Sanada, L. Le and K. Hori, Macromolecules, 2016, 49, 2511-2517.

37. Y.-a. Wang, Y. Shi, Z. Fu and W. Yang, Polym. Chem., 2017, 66. 8, 6073-6085.

38.

A. Goto, A. Ohtsuki, H. Ohfuji, M. Tanishima and H. Kaji, J. Am. Chem. Soc., 2013, 135, 11131-11139.

39. L. Lei, M. Tanishima, A. Goto, H. Kaji, Y. Yamaguchi, H. Komatsu, T. Jitsukawa and M. Miyamoto, Macromolecules, 2014, 47, 6610-6618.

40. A. Ohtsuki, L. Lei, M. Tanishima, A. Goto and H. Kaji, J. Am. Chem. Soc., 2015, 137, 5610-5617.

41. C.-G. Wang, F. Hanindita and A. Goto, ACS Macro Lett., 2018, 7, 263-268.

42.

A. Goto, M. Tanishima, Y. Nakajima, A. Ohtsuki, L. Lei and $\mathrm{H}$. Kaji, in Controlled Radical Polymerization, Vol 1: Mechanisms, eds. K. Matyjaszewski, B. S. Sumerlin, N. V. Tsarevsky and J. Chiefari, 2015, vol. 1187, pp. 171-182.

43. J. Sarkar, L. Q. Xiao and A. Goto, Macromolecules, 2016, 49, 5033-5042.

44. L. Xiao, K. Sakakibara, Y. Tsujii and A. Goto, Macromolecules, 2017, 50, 1882-1891.

45. X. Liu, Q. Xu, L. Zhang, Z. Cheng and X. Zhu, Polym. Chem., 2017, 8, 2538-2551.

46. C.-G. Wang and A. Goto, J. Am. Chem. Soc., 2017, 139, 10551-10560.

47.

H. Fischer, Chem. Rev., 2001, 101, 3581-3610.

48.

. Ding X. W. Jiang J. Y. Peng L. F. Zhang, Z. P. Cheng and X. L. Zhu, Macromol. Rapid Comm., 2015, 36, 538-546.

49. P. K. Muhuri, S. K. Ghosh and D. K. Hazra, J. Chem. Eng Data, 1993, 38, 242-244.

50. C. R. Evertz and R. Livingston, J. Phys. Colloid Chem., 1949, 53, 1330-1333.

51. W. E. S. Turner and C. C. Bissett, J. Chem. Soc., Trans., 1913, 103, 1904-1910

52.

W. Jakubowski and K. Matyjaszewski, Angew. Chem. Int. Ed., 2006, 45, 4482-4486.

53. B. Braida and P. C. Hiberty, J. Phys. Chem. A, 2000, 104, 4618-4628.

54. D. W. Smith, J. Chem. Educ., 1990, 67, 559-562.

55. P. B. D. de la Mare and B. E. Swedlund, ed. S. Patai, Wiley, New York, 1973, vol. 1, p. 460.

56. R. D. Pace and Y. Regmi, J. Chem. Educ., 2006, 83, 13441348.

57.

C. Y. Lin, M. L. Coote, A. Petit, P. Richard, R. Poli and K. Matyjaszewski, Macromolecules, 2007, 40, 5985-5994.

58. S. Beuermann, M. Buback, T. P. Davis, R. G. Gilbert, R. A Hutchinson, O. F. Olaj, G. T. Russell, J. Schweer and A. M. vanHerk, Macromol. Chem. Phys., 1997, 198, 1545-1560.

59. W. Tang, Y. Kwak, W. Braunecker, N. V. Tsarevsky, M. L. Coote and K. Matyjaszewski, J. Am. Chem. Soc., 2008, 130, 10702-10713.

60. C. Y. Lin, M. L. Coote, A. Gennaro and K. Matyjaszewski, J. Am. Chem. Soc., 2008, 130, 12762-12774.

61. S. Yamago, K. Lida and J. Yoshida, J. Am. Chem. Soc., 2002, 124, 13666-13667.

62

S. Maria, F. Stoffelbach, J. Mata, J.-C. Daran, P. Richard and R. Poli, J. Am. Chem. Soc., 2005, 127, 5946-5956.

63. Y. Zhang, K. Schröder, Y. Kwak, P. Krys, A. N. Morin, T. Pintauer, R. Poli and K. Matyjaszewski, Macromolecules, 2013, 46, 5512-5519.

64. S. G. Gaynor, J. S. Wang and K. Matyjaszewski, Macromolecules, 1995, 28, 8051-8056.
65. A. Robb, J. R. Cheeseman, G. Scalmani, V. Barone, B. Mennucci, G. A. Petersson, H. Nakatsuji, M. Caricato, X. Li, H. P. Hratchian, A. F. Izmaylov, J. Bloino, G. Zheng, J. L. Sonnenberg, M. Hada, M. Ehara, K. Toyota, R. Fukuda, J. Hasegawa, M. Ishida, T. Nakajima, Y. Honda, O. Kitao, H. Nakai, T. Vreven, J. Montgomery, J. A., J. E. Peralta, F. Ogliaro, M. Bearpark, J. J. Heyd, E. Brothers, K. N. Kudin, V. N. Staroverov, R. Kobayashi, J. Normand, K. Raghavachari, A. Rendell, J. C. Burant, S. S. Iyengar, J. Tomasi, M. Cossi, N. Rega, N. J. Millam, M. Klene, J. E. Knox, J. B. Cross, V. Bakken, C. Adamo, J. Jaramillo, R. Gomperts, R. E. Stratmann, O. Yazyev, A. J. Austin, R. Cammi, C. Pomelli, J. W. Ochterski, R. L. Martin, K. Morokuma, V. G. Zakrzewski, G. A. Voth, P. Salvador, J. J. Dannenberg, S. Dapprich, A. D. Daniels, Ö. Farkas, J. B. Foresman, J. V. Ortiz, J. Cioslowski and D. J. Fox, Gaussian 09, Revision D.01, Gaussian, Inc., Wallingford CT, 2009.

67. A. D. Becke, J. Chem. Phys., 1993, 98, 5648-5652.

68. S. Grimme, J. Antony, S. Ehrlich and H. Krieg, J. Chem. Phys., 2010, 132, 154104

69. L. E. Roy, P. J. Hay and R. L. Martin, J. Chem. Theory Comput., 2008, 4, 1029-1031.

70. J. George and N. V. Sastry, Int. J. Thermophys., 2003, 24, 1697-1719.

71. V. S. Bryantsev, M. S. Diallo and W. A. Goddard, III, J. Phys. Chem. B, 2008, 112, 9709-9719. 